Document downloaded from:

http://hdl.handle.net/10251/66305

This paper must be cited as:

Serrano Cruz, JR.; Olmeda González, PC.; Arnau Martínez, FJ.; Reyes Belmonte, MA.; Lefebvre, A. (2013). Importance of Heat Transfer Phenomena in Small Turbochargers for Passenger Car Applications. SAE International Journal of Engines. 6(2):1-13. doi:10.4271/2013-01-0576.

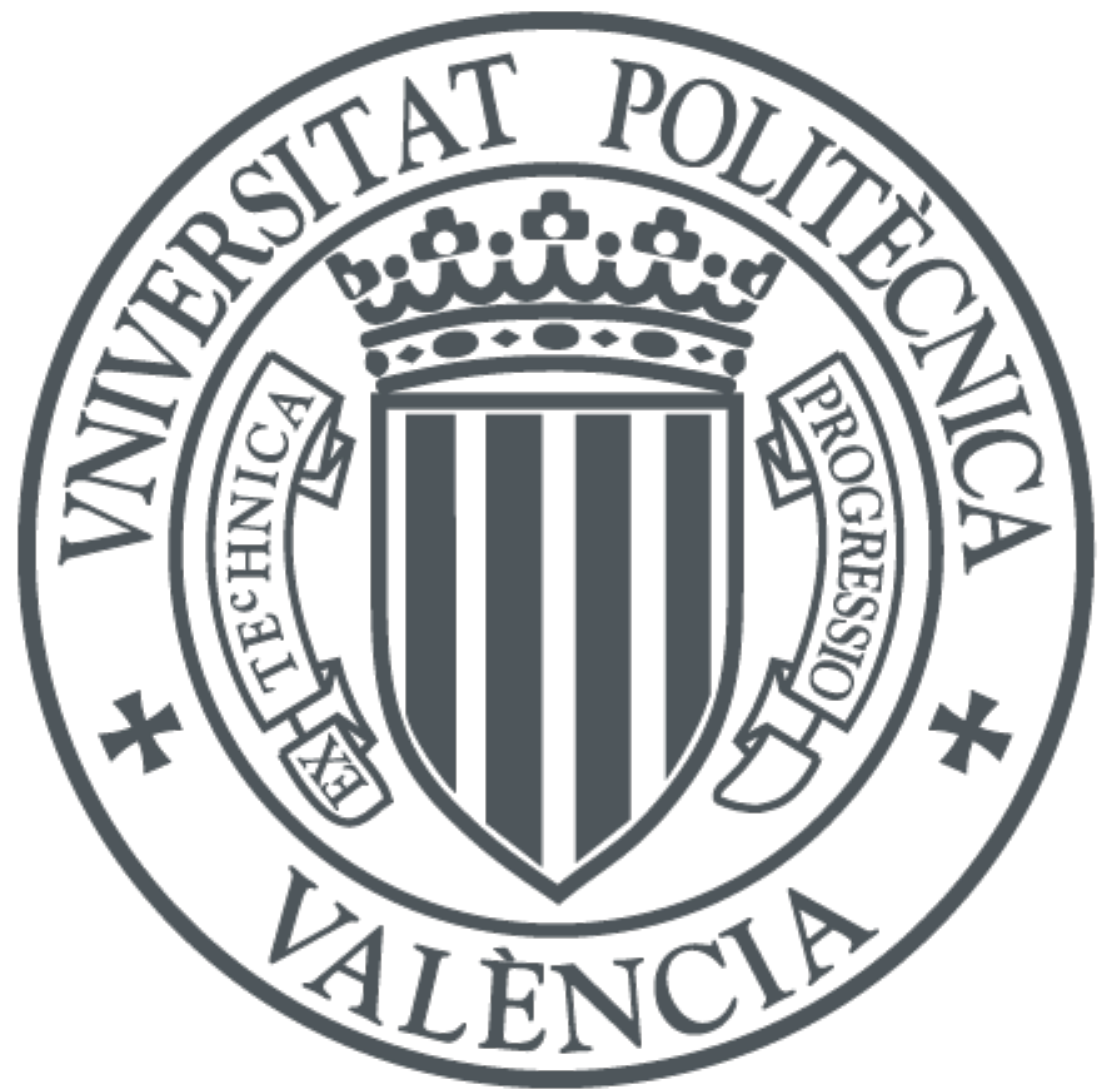

The final publication is available at

http://dx.doi.org/10.4271/2013-01-0576

Copyright SAE International

Additional Information 


\title{
Importance of heat transfer phenomena in small turbochargers for passenger car applications
}

\author{
J. R: Serrano, P. Olmeda, F. Arnau, M.A. Reyes-Belmonte \\ CMT-Motores Térmicos-Universitat Politècnica de Valencia \\ A. Lefebvre \\ Renault SAS
}

\begin{abstract}
$\underline{\text { ABSTRACT }}$
Nowadays turbocharging the internal combustion engine has become a key point in the reduction on pollutant emissions and the improvement on engine performance. The matching between the turbocharger and the engine is vital due to the highly unsteady flow the turbocharger works with. In the present paper the importance of the heat transfer phenomena inside small automotive turbochargers will be analyzed. This phenomenon will be studied from the point of view of both the turbine and the compressor in one-dimensional modelling. The goodness of the model will be demonstrated predicting turbine and compressor outlet temperatures. An accurate prediction of these parameters will be key designing the intercooler and the after treatment devices. A series of tests in a gas stand with steady and pulsating hot flow in the turbine side will be modeled to show the good agreement in turbocharger enthalpies prediction.
\end{abstract}

\section{INTRODUCTION}

Traditionally heat transfer effects have been neglected in turbomachinery studies due to the relative small exchange surface and the occurring high flows. Nevertheless this assumption is only valid for large turbomachines, but not true for the small turbochargers used in passenger car applications, mainly at low load operative points and transient conditions $[1,2]$. Such conditions correspond to urban traffic conditions according to NEDC tests (New European Driving Cycle) where the turbocharger speed is less than $90,000 \mathrm{rpm}$. In such conditions heat transfer to the compressor (from the turbine and oil) can be equal to the energy transferred by the compression process [3]. Improvement in turbocharger simulation codes and engine matching becomes vital in the automotive division since turbocharging the downsized engines is the only feasible way to reduce fuel consumption and pollutant emissions [4,5]. Nevertheless, the information provided by turbocharger manufacturers is not usually measured under adiabatic conditions due to the difficulties and limitations of such testing procedure. So the efficiency given in a turbocharger map is not the one defined as isentropic as it also contains the influence of heat. Nonetheless if the overall simulation of the turbocharger wants to be improved it will be desirable obtaining information about isentropic efficiency. It is due to it will remain the same for any given configuration (in a gas stand or in an engine) because it is subject only to the internal gas dynamic processes occurring in the machine. If a

Page 1 of 12 direct parameterization of the turbocharger using extrapolation from turbocharger maps information is used, unsatisfactory modeling results will be obtained as showed by [6].

For the aforementioned reasons having a turbocharger Heat Transfer Model (HTM) would be crucial when manufacturer maps are used. That case is the standard for engine simulation codes. In such conditions the HTM will provide the turbocharger isentropic efficiency by discounting the heat fluxes occurring when the map was measured.

Looking insight of the heat transfer phenomena in turbochargers, several studies have shown that the turbocharger is part of a complex thermal system containing different heat flows between compressor, turbine, engine housing, lubrication oil and environment [7,8]. In normal operative conditions heat flows from the turbine to the turbocharger housing and later arrives to the compressor worsening its efficiency $[9,10,11,12]$. For instance when turbine inlet temperature increases from $50^{\circ} \mathrm{C}$ to $500^{\circ} \mathrm{C}$ a nearly $15 \%$ lower compressor efficiency is measured for turbocharger speeds lower than the $50 \%$ of the maximum tip speed [13]. In the housing the heat is partially removed by the lubricating oil and the coolant circuit in case it exists. In addition the turbocharger exchanges energy to the surroundings by means of radiation and a mixed convection (free and forced depending on the set-up). A schematic diagram of these fluxes of energy can be observed in Figure 1. Several methodologies to characterize heat transfer phenomena in turbochargers have been proposed in the literature survey. They range from fast one-dimensional models for the whole turbocharger to the accurate conjugated FEM-CFD models that analyze the separated components of the turbocharger. One-dimensional models to characterize both the internal and external heat transfer of turbochargers are based in the thermodynamic analysis of adiabatic and diabatic processes of the turbocharger. Figure 2 shows both processes compared with the ideal one (isentropic). 


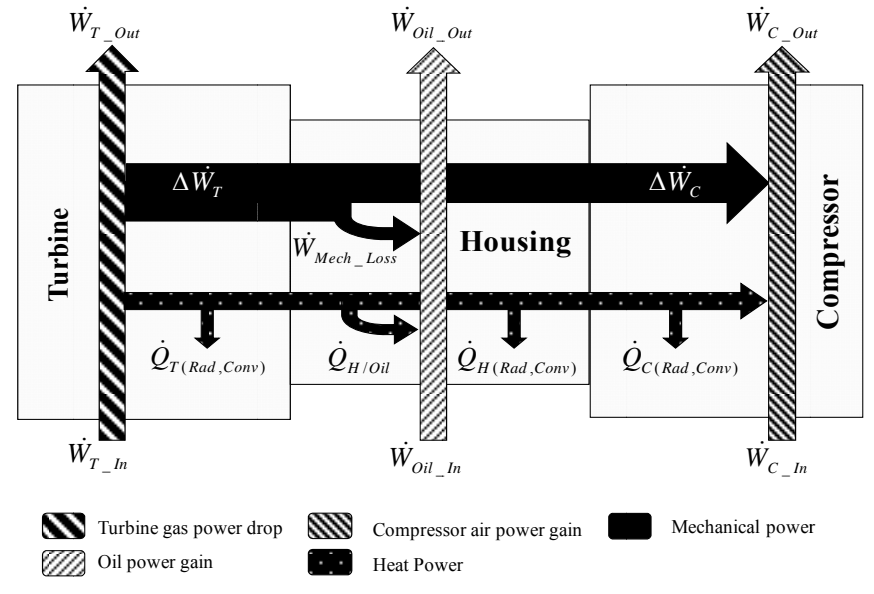

Figure 1. Main energy fluxes inside a turbocharger.

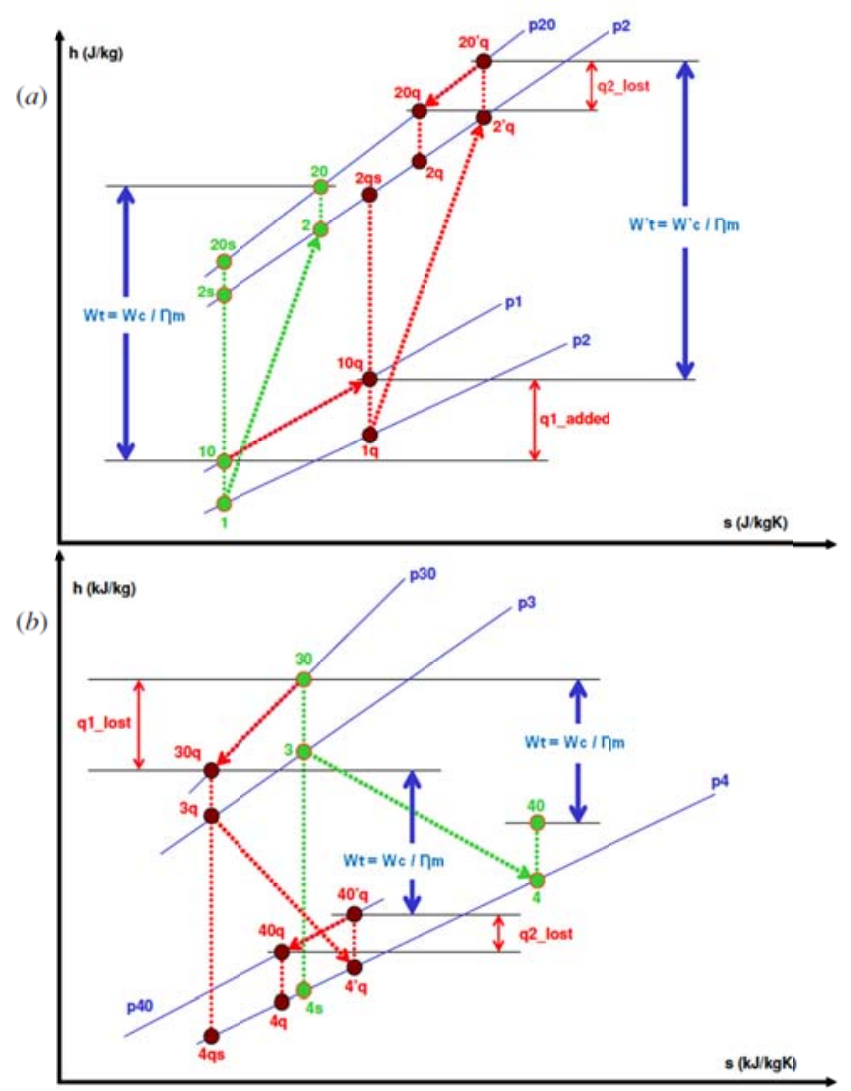
Figure 2. Entropic diagram for the compressor (a) and
turbine (b)

The isentropic evolution, from 1 to $20_{\mathrm{s}}$ (Figure 2-a), reflects the ideal situation where the compression process will take place under the assumptions of being adiabatic and reversible. Compressor outlet temperature in this situation will be calculated using the isentropic evolution statement and state equation between the inlet and outlet conditions [14]. If the compressor process is assumed to be adiabatic but not reversible, compressor outlet temperature $\left(\mathrm{T}_{20}\right)$ will increase compared to the isentropic case. The ratio of enthalpy changes between both processes is known as compressor isentropic efficiency. Furthermore, if it is assumed that compressor is receiving some heat flux from the turbocharger unit (whether the turbine case or the lubricating oil), its real outlet temperature will be even higher $\left(\mathrm{T}_{20}\right.$ ' $)$ than the adiabatic outlet temperature $\left(\mathrm{T}_{20}\right)$. In the case showed in that figure, air at the compressor inlet $\left(\mathrm{T}_{10}\right)$ will receive a heat flux that will increase its temperature $\left(\mathrm{T}_{10 \mathrm{q}}\right)$. Later, the compression process will take place $\left(\mathrm{T}_{20}\right.$, $)$ and finally the temperature at the compressor outlet will be reduced as a consequence of losing a heat flux to the cooler housing $\left(\mathrm{T}_{20 \mathrm{q}}\right)$. At low rotational speeds, thermal energy will be transferred to the compressor. At moderate and high rotational speeds compressor also receives heat from the turbocharger housing but at certain point compressed air temperature will be higher than casing temperature and heat transfer will take place from the air to the compressor casing and later to the surroundings reducing its temperature $\left(\mathrm{T}_{20 \mathrm{q}}\right)$. Hence the compressor cannot be considered as adiabatic under any circumstances [15]. Nevertheless heat transfer effects will be minor at high rotational speeds if compared with its mechanical power. A New efficiency could be defined between the ratio of enthalpy changes between the ideal situation and the real one $\left(T_{20 q}-T_{10}\right)$. This efficiency is known simply as compressor efficiency and is typically provided by manufacturer maps. One of the consequences of this thermal energy transferred to the compressor will be the reduction in compressor efficiency given in manufacturer maps due to the increase in outlet temperature that can lead to an underestimation of turbocharger speed when computing it from solving the energy balance in the turbocharger. That temperature increase must be taken into account for the intercooler designs, this effect will become important at engine starting, no-load and partial-load engine operation. In those situations heat transfer to the compressor will increase due to the low rotational speeds and the proximity of engine operating points to the compressor surge line [16].

The same processes can be distinguished during turbine operative conditions. In this case as shows Figure 2-b, the reversible and adiabatic expansion process (isentropic) is shown between points 30 and $4 \mathrm{~s}$. Turbine isentropic outlet temperature can be calculated, if the expansion process keeps adiabatic but not reversible, then another final state is defined with the name of adiabatic (point 4). The ratio of enthalpy change between the adiabatic and the isentropic states will be used to define the turbine isentropic efficiency. If diabatic evolution is considered (between points 30 and $40 q$ ), turbine outlet temperature will be lower than it would be for the work transfer alone predicted by the isentropic one. That is justified as the real evolution is cooled due to heat transfer losses and so turbine efficiency defined between both states will be higher than the adiabatic. In case the reduction in turbine outlet temperature due to the heat transfer exceeds the increase in temperature due to internal inefficiencies of the turbine, turbine outlet temperature could be lower than the adiabatic

Page 2 of 12 
one and the adiabatic efficiency traditionally defined would be higher than one.

One of the discrepancies between proposed one-dimensional models in the literature to characterize heat transfer phenomena in turbochargers is whether the heat flux is removed from the system after or before the extraction of power, or even a combination of both possibilities. Baines et al. [17] assumes that the heat transferred from the compressed air to the surroundings and to the rest of the turbocharger unit occurs after the compression process, placed in the diffuser and the volute. This explanation is justified by the larger surface exposed to the air in this place compared to the impeller area. Although heat transfer must exist in the impeller due to conduction along the shaft, it will be small due to the lubrication oil and the small diameter of the shaft. That hypothesis is also confirmed by the fact that compressor constant speed lines are not modified when the turbine inlet temperature increases, what ensures that aerodynamic losses do not depend on the heat fluxes [18]. However efficiency lines show important changes what confirms the existence of a heat flux from the hot turbine to the cold compressor. Those differences are bigger at the low load area, where the compressor is far away from the hypothesis of adiabatic machine. As the heat transfer only occurs after the impeller, the mechanical power measured in adiabatic conditions will be the same whatever will be turbine inlet temperature. The model proposed by Baines et al. [17] is only focused in heat transfer phenomena of the turbocharger based on convection process. Using the same argument of comparing exposed areas, in the turbine the bigger heat transfer will take place up to turbine tongue and at volute and so before extracting power in the rotor. In this case heat transfer will affect the work transfer process. The main advantage of this technique is the simplicity for latter programming in an engine computational code, as the whole heat transfer takes place only in one place. In addition experimental instrumentation will be easier and so the validation of the model. Models proposed by Bohn [19] and Shaaban $[15,20]$ make a distinction between the heat transfer that takes place after and before the rotor. With this level of detail, difficulties in instrumentation for experimental characterization increases. Values from literature about thermal conductivity of all casing materials and surface emissivity were used by Bohn et al. [21] instead of a global turbocharger characterization. Internal convection between each of the working fluids (exhausted gases, air and oil) to the corresponding cases (turbine, compressor and housing case) was characterized by means of a general equation based on Nusselt number but fitting constants from that equation using experimental data. The study of Bohn et al. [21] revealed the importance of the lubricating oil working as a sink removing part of the internal heat transfer from the turbine side to the compressor side. The importance of the lubricating oil is also confirmed as compressor heat flux is not so strong dependent with turbine inlet temperature. Similar results were obtained by Yamagata [22] but only focusing in high turbocharger speeds without thermal insulation. The study concludes that metal temperatures of compressor components (back plate,

Page 3 of 12 impeller back and impeller hub) varied proportionally to the compressed air temperature released by compressor, being the effects of turbine inlet temperature relatively small.

Models presented by Sidorow et al. [23] and Romagnoli et al. [24] propose the division of compression and expansion processes into three stages. For the compressor it is considered that the heat transfer takes place at two locations on the flow path according to [8]. A first heat flux increases compressor temperature before the compression process. After that the adiabatic compression occurs. Finally a heat flux source after the compression will increase the adiabatic outlet temperature up to the measured temperature. The same approach is considered for the turbine, assuming that the diabatic expansion process is divided into three stages. Firstly a heat flux is released at turbine inlet conditions, next adiabatic expansion occur; finally another release of heat flux occurs.

In the present paper the importance of internal heat transfer inside automotive turbochargers will be analyzed. For that purpose two different turbochargers in size and configuration will be studied under steady and pulsating hot flow conditions at the turbine side. The importance of including a HTM in 1D engine simulation code will be observed in the prediction of turbocharger power balances and also in compressor and turbine outlet temperatures prediction.

\section{TURBOCHARGER HEAT TRANSFER MODEL DESCRIPTION}

In order to study heat transfer phenomena inside the turbocharger it has been divided into several measurement planes. Those planes are introduced according to the big temperatures differences between the hot turbine, the "cold" compressor and the lubricating oil passing through the central housing [19,21]. Those differences force a heat flux from the hot side (the turbine) to the cold side, typically the oil but also to the compressor for low load regions. Differences in radial surface temperature are small compared to the axial distribution what allows the simplification of the internal heat transfer problem into the 1D hypothesis [20].

\section{Lumped Model}

The proposed turbocharger thermal model is based on the electrical analogy [25]. In this kind of models, the turbocharger is considered as a thermal network consisting in a finite number of nodes, whose thermal inertia is characterized by a thermal capacitance, and linked with other nodes by means of thermal conductance. Once the structure is divided into nodes, the energy conservation equation can be written for each node. It means the sum of heat fluxes between nodes, convective heat fluxes and other heat fluxes in a time interval equals the change in sensible energy of the node (1). 
$m_{i} \cdot c_{v} \cdot \frac{T_{t+\Delta t}^{i}-T_{t}^{i}}{d t}=\sum_{j} K_{i j} \cdot\left(T_{t+\Delta t}^{j}-T_{t+\Delta t}^{i}\right)+\sum_{k} q_{k \rightarrow i}+\ldots$

$\sum_{l} h_{l i} \cdot A_{l i} \cdot\left(T_{t+\Delta t}^{l}-T_{t+\Delta t}^{i}\right)$

Writing equation (1) for each of the $n$ nodes gives a set of linear, implicit equations of the form,

$$
\left(K+\frac{1}{\Delta t} \cdot C\right) \cdot T_{t+\Delta t}=Q+\frac{1}{\Delta t} \cdot C \cdot T_{t}+H
$$

In stationary conditions $(\mathrm{t}=\mathrm{t}+\Delta \mathrm{t})$, equation (2) reduces to:

$$
K \cdot T_{t}=Q+H
$$

If boundary conditions are added to equation temperatures, $\mathrm{T}_{\mathrm{bc}}$ and rearranging it can be obtained:

$$
\left[\begin{array}{cc}
I & 0 \\
H & K
\end{array}\right] \cdot\left[\begin{array}{c}
T_{b c} \\
T_{\text {unknown }}
\end{array}\right]=\left[\begin{array}{c}
T_{b c} \\
0
\end{array}\right]
$$

The proposed one-dimensional lumped model for the automotive turbocharger consists on a thermal resistor network presented in Figure 3. There are 5 metal nodes named $\mathrm{T}, \mathrm{H} 1, \mathrm{H} 2, \mathrm{H} 3$ and $\mathrm{C}$ corresponding to the cases for the turbine, housing and compressor [26,27]. Housing case has been split into three measurement planes, one near the turbine (H1) other near the compressor back plate (H3) and the other in the center of the housing (H2). That division is justified by the complexity of housing internal geometry and the later simplicity of studying the internal heat fluxes with the lubricating oil and the coolant circuit in that kind of turbochargers. The boundary conditions are represented by five convective nodes; turbine gas (IT), lubrication oil (oil), and compressed air (IC-OD), ambient and cooling liquid (W) in case it exists. These nodes are characterized by their average temperatures and film coefficients.

\section{Model Information}

Metal nodes are connected between them by means of conductive conductance $K_{i, j}$ being calculated the heat flux using Fourier's Law (5).

$\dot{Q}_{i, j}^{\text {cond }}=K_{i, j} \cdot\left(T_{i}-T_{j}\right)$

Conductive conductance between adjacent metal nodes in the turbocharger will be constant for any operative condition as this property only depends on internal geometry and material. Metal nodes can store heat energy during transient performance introducing thermal capacitances in order to simulate that effect. Those properties will be obtained on a

Page 4 of 12 specific test bench [26,28] following the methodology described in [27].

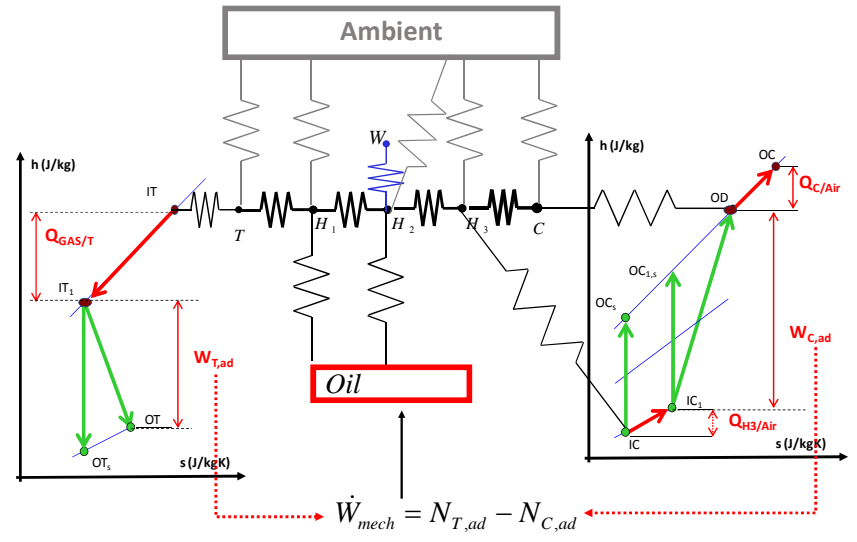

Figure 3. One-dimensional lumped model for a turbocharger with coolant circuit.

Metal nodes are connected with fluid nodes (working fluids or ambient) by means of convective conductance $h A_{l, i}$ being calculated the heat flux using Newton's cooling law (6).

$\dot{Q}_{i, j}^{c o n v}=h A_{i, j} \cdot\left(T_{i}-T_{j}\right)$

Convective conductance will depend on turbocharger geometry (wetted surface) but also on turbocharger operative conditions (fluid velocity and temperature). Thermal correlations for those heat transfer paths will be wisely determined from turbocharger measures under steady hot flow conditions. Those correlations will be based on Nusselt' number definition assuming that turbocharger internal cases (turbine and compressor volutes, lubricating ports and cooling ports) can be modeled as single pipes. With that assumption Nusselt number correlations will be in the form of DittusBoelter (7) and Sieder-Tate (8) correlations [29].

$\mathrm{Nu}_{D}=0.023 \operatorname{Re}_{D}^{4 / 5} \operatorname{Pr}^{n}$

$\mathrm{Nu}_{D}=0.027 \operatorname{Re}_{D}^{4 / 5} \operatorname{Pr}^{1 / 3}\left(\frac{\mu}{\mu_{s}}\right)^{0.14}$

Those expressions are based on the simplicity of forced convection inside smooth and long pipes but these assumptions cannot be confirmed when studying internal heat transfer of the turbocharger (complex geometry, not smoothy, short pipes). For that reason the aforementioned expressions cannot be used in its original fashion. However it is desided to keep generallity in the study and so only the constant coefficients and exponents of these correlations will be recalculated for any of the convective branches. That calculation will be done by a simple fitting using experimental data from hot steady flow tests [9]. Figure 4shows the 
modelled Nusselt number (in lines) after the fitting procedure from constants in equation (7), as it is observed the model is able to catch most of the experimental measured points for both turbochargers and in a wide range of operative conditions.

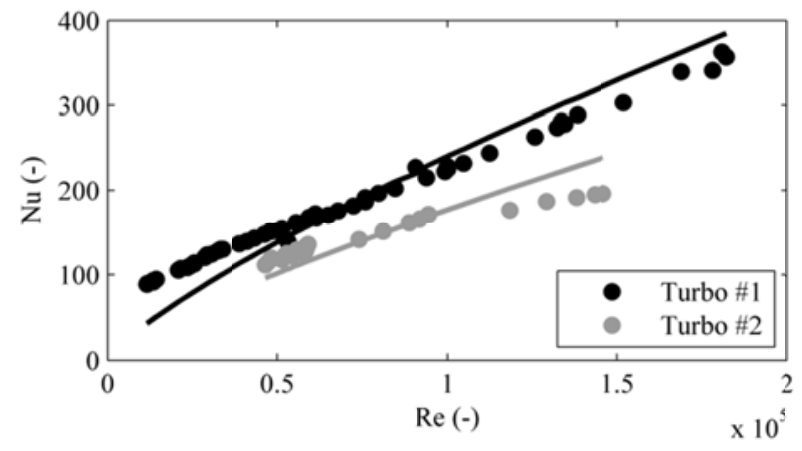

Figure 4. Modelled Nusselt number for steady hot tests (turbochargers 1 \& 2)

In order to close the thermal analysis of the turbocharger a source term will be used to consider the heat transferred from/to the lubricating oil but only due to the mechanical losses produced by friction. That model results are further discussed in [30]. Oil tempearature will increase due to friction but also due to convection between lubricating oil and housing nodes through the lubrication internal ports.

Once conductive and convective conductances, nodes capitances and mechanical losses have been determined HTM will be prepared to be used in turbocharger simulations. For this paper the 1D gas dynamic open code for engine simulation, OpenWAM [31,32] has been used. The turbocharger model used by OpenWAM is shown in Figure 5. Besides, performance maps for both the turbine and the compressor have been measured under adiabatic steady conditions and will be used coupled with the HTM in order to calculate turbocharger outlet conditions.

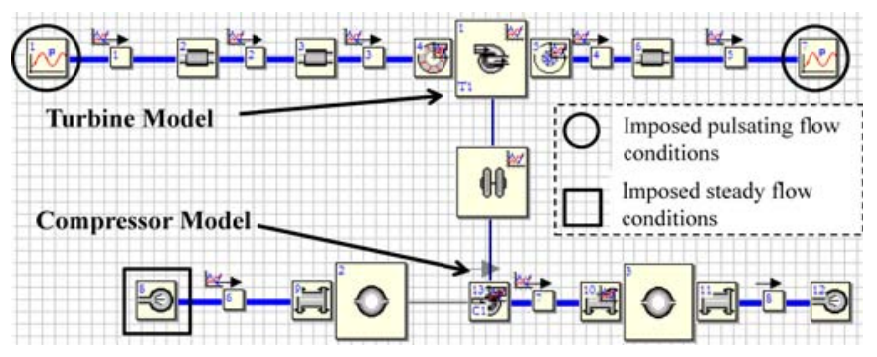

Figure 5. Turbocharger model in OpenWAM.

The turbocharger model used by OpenWAM integrates different submodels to account for mechanical losses due to friction [30], lumped model for the heat transfer effects [9], extrapolation techiques to extend manufacturer maps [33] and geometrical models for the compressor [34,35] and turbine
[36] to account for accoustic effects. The proposed HTM will consider that the heat transfer between exhaust gases and the turbine case only occurs before the work exchange. That simplification is supported by its higher exchange surface. That heat flux will be transmitted to the part of the housing nearest to the turbine case (node H1) and later to the rest of housing nodes passing to the oil and cooling circuit. The heat transfer process in the compressor is divided in two stages. As the lumped model shows (Figure 3) the air passing through the compressor can receive heat from compressor case (branch $\mathrm{C}$ OD) or from the back plate (branch $\mathrm{H} 3-\mathrm{IC}$ ).

Two turbochargers for diesel passenger car applications have been analyzed being their main properties shown in Table 1 . Hot steady tests were later simulated using the turbocharger model integrated in OpenWAM, results analysis will be done through next sections. All tests were performed with the turbocharger fully insulated and without ventilation, so external heat transfer due to free convection and radiation can be neglected.

\begin{tabular}{|c|c|c|}
\cline { 2 - 3 } \multicolumn{1}{c|}{} & Turbo \#1 & Turbo \#2 \\
\hline $\begin{array}{c}\text { Turbine Wheel } \\
\text { Diameter }\end{array}$ & $40 \mathrm{~mm}$ & $36 \mathrm{~mm}$ \\
\hline $\begin{array}{c}\text { Compressor Wheel } \\
\text { Diameter (inducer) }\end{array}$ & $54 \mathrm{~mm}$ & $47 \mathrm{~mm}$ \\
\hline VGT & Yes & Yes \\
\hline Coolant circuit & Yes & No \\
\hline
\end{tabular}

Table 1 - Turbochargers geometry

\section{Lumped Model Adaptation}

The turbocharger model presented here has been validated for both turbochargers with and without cooling circuits. In the case of the cooled turbocharger the same model is valid by adding an extra branch connecting housing central node (H2) to the cooling node W (Figure 3 ). This node will include boundary conditions i.e. coolant inlet temperature and mass flow. In this case heat transfer to the oil branches are less important due to the water flow is working as a heat sink as it was said before. Capabilities of the original model including cooling branch will be discussed in the following section.

\section{HEAT TRANSFER EFFECTS}

\section{Importance of heat fluxes}

Figure 6 shows the importance of internal heat fluxes of the turbocharger versus the turbine experimental enthalpy drop. Heat fluxes have been expressed in dimensionless form versus the experimental enthalpy drop of the fluid governing the heat transfer phenomena. It is observed how heat fluxes become less important as turbine power increases. For really low loads (points from the NEDC homologation driving cycle) heat losses inside the turbine case (named $\mathrm{Q}_{\mathrm{GAS} / \mathrm{T}}$ ) can reach the $50 \%$ of the turbine gas power drop calculated as the global 
enthalpy drop. Those heat losses $\left(\mathrm{Q}_{\mathrm{GAS} / \mathrm{T}}\right)$ will be transferred completely from the turbine case (node $\mathrm{T}$ ) to the side of the housing nearest to the turbine (node $\mathrm{H} 1$ ) as turbochargers were externally fully insulated. For that reason no heat losses to the ambient were expected and only internal heat transfer phenomena was observed. Regarding the power to the oil due to the internal heat fluxes $\left(\mathrm{Q}_{\mathrm{H} 1 / \mathrm{Oil}}, \mathrm{Q}_{\mathrm{H} 2 / \mathrm{Oil}}\right)$ compared with the experimental oil enthalpy drop, it is observed that relative importance of heat fluxes to the oil increases as turbine power reduces. In other words, power to the oil due to mechanical losses at low loads is less important than internal heat fluxes. Nevertheless, as turbine load increases the importance of internal heat fluxes to the oil decreases compared with the global oil enthalpy drop (that includes power due to mechanical losses but also heat transfer effects). It is also observed how for a non-cooled turbocharger heat fluxes to the oil are more important than for a cooled turbocharger, what confirms that water acts as a sink. It is important also the role of the cooling liquid in case it exists, for low load conditions heat removed by cooling port can reach a $60 \%$ of the turbine gas power drop. Following the thermal network model of the turbocharger presented in Figure 3 it is observed how most of the heat losses from exhaust gases moving to the turbine case are recovered by the cooling port (for turbocharger 1). Since both fluxes $\left(\mathrm{Q}_{\mathrm{T} / \mathrm{Gas}}\right.$ and $\left.\mathrm{Q}_{\mathrm{H} 2 / \mathrm{W}}\right)$ are similar in magnitude if they are compared with turbine gas power drop. That effect will be observed too in oil branches, as in case of a cooled turbocharger the heat recovered by lubricating oil drastically reduces compared with a non-cooled turbocharger.

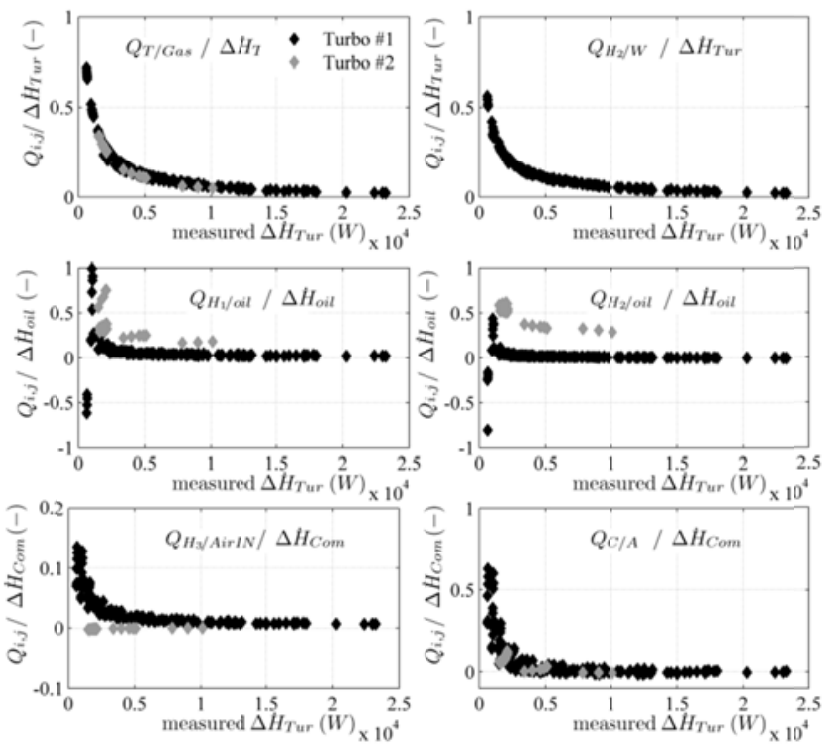

\section{Figure 6. Importance of internal heat transfer for both turbochargers}

Regarding with the compressor it is observed how the moving air absorbs energy from node $\mathrm{C}$ representing compressor case $\left(\mathrm{Q}_{\mathrm{C} / \mathrm{A}}\right)$. That situation occurs for medium to low loads as it is showed in Figure $6\left(\mathrm{Q}_{\mathrm{C} / \mathrm{A}} / \Delta \dot{\mathrm{H}}_{\mathrm{Com}}\right)$. In those conditions Page 6 of 12 lubricating oil is hotter than compressed air and the heat transfer mechanism moves to increase the compressor outlet temperature. When compressor load increases (higher compression ratios and mass flows) compressor outlet temperature is higher than lubricating oil and the mechanism is reversed. In this case the heat flux will move from node $\mathrm{C}$ to $\mathrm{H} 3$ and so it is represented as negative as the direction showed by subscripts is mandatory. That phenomenon can be observed in Figure 7 contour maps but only for the energy fluxes that are removed and introduced to compressor case. That representation shows clearly in which region of the turbocharger maps occurs the change in the heat path.
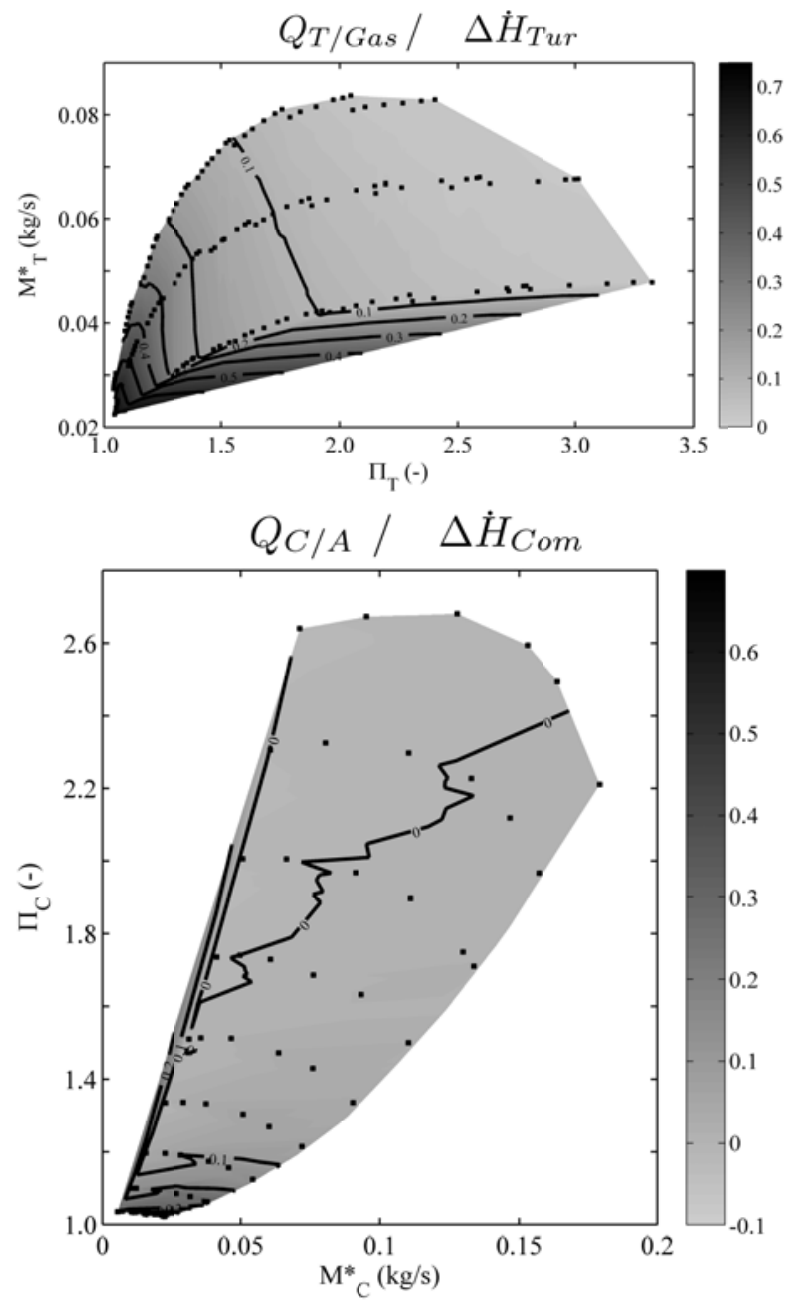

Figure 7. Heat Fluxes influence in Turbine and Compressor

\section{Discussion of steady flow results}

In this section the influence of including the HTM for the turbocharger in 1D simulation is analyzed. For that purpose steady hot flow tests have been done in a gas stand. Those points correspond to the measurement of compressor/turbine performance maps with an inlet temperature up to $470{ }^{\circ} \mathrm{C}$ as 
showed in Figure 8. The influence of taking into account the proposed HTM has been analyzed comparing simulations results when the HTM is activated or not. Discussion is done analyzing outlet temperature prediction; a small difference between measured and predicted temperatures is desired. A good turbine outlet temperature prediction is vital due to aftertreatment devices. Accuracy predicting compressor outlet temperature will be also important due to its relation with intercooler design and the engine volumetric efficiency.

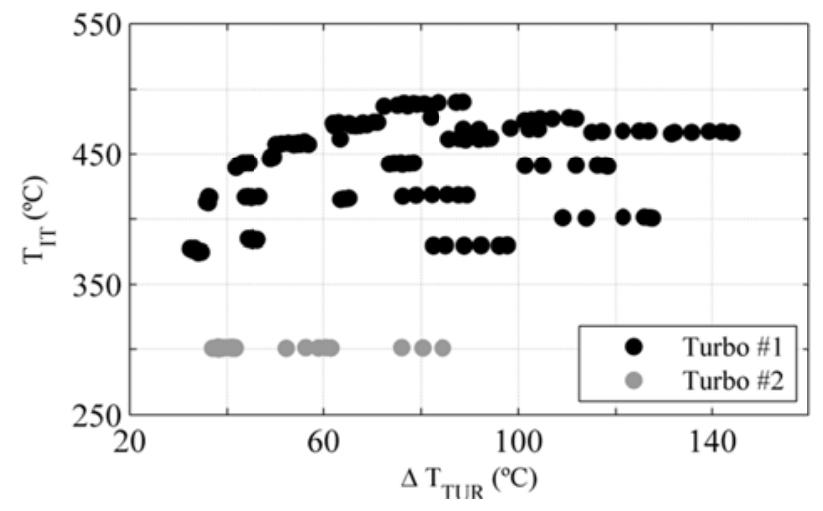

Figure 8. Experimental Turbine inlet temperature vs. total temperature drop.

Error predicting outlet temperatures in both the compressor and turbine are defined in absolute values as shown in equations (9) and (10).

$$
\begin{gathered}
e T O T\left({ }^{\circ} C\right)=T_{O T}^{\text {model }}-T_{O T}^{\text {measure }} \\
e \operatorname{COT}\left({ }^{\circ} C\right)=T_{O C}^{\text {model }}-T_{O C}^{\text {measure }}
\end{gathered}
$$

Errors predicting outlet temperature (eTOT and eCOT) are represented versus the measured temperature drop as defined in equations (11) and (12).

$$
\begin{aligned}
& \Delta T_{C}\left({ }^{\mathrm{o}} C\right)=T_{O C}^{\text {measure }}-T_{I C}^{\text {measure }} \\
& \Delta T_{T}\left({ }^{\mathrm{o}} C\right)=T_{I T}^{\text {measure }}-T_{O T}^{\text {measure }}
\end{aligned}
$$
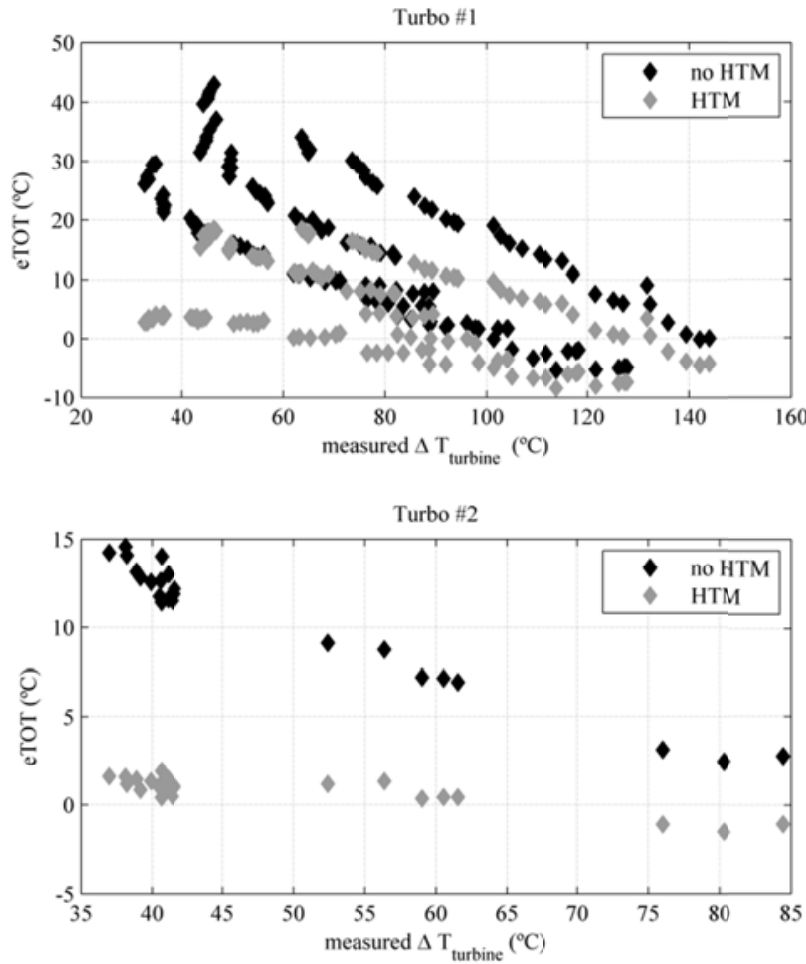

Figure 9. Error predicting turbine outlet temperature, influence of using HTM.

In Figure 9 error predicting turbine outlet temperature is shown versus the measured temperature drop and in Figure 10 versus frequency distribution graphics. Distinction between lower and higher loads has been done in Figure 10 that representation (grey is used for low load points and black for high loads). It has been observed that for compressor temperature gains below $60^{\circ} \mathrm{C}$ compressed air receives heat from the housing (low load points) and for temperature gains over $60^{\circ} \mathrm{C}$ compressed air released energy to the housing (high load points). As Figure 9 shows when the HTM is used eTOT drastically reduces. In the case of the turbocharger \#2 error distribution is clearly centered on zero deviation. In the case of turbo \#1 errors above $20^{\circ} \mathrm{C}$ predicting turbine outlet temperature disappear, and most of simulations are below the threshold of $5^{\circ} \mathrm{C}$ for low load points. In the case of turbocharger \#2 eTOT practically disappears, mainly for the low load points as Figure 9 shows. This fact ensures the accuracy of the model, as it is in that region where heat fluxes become more important to engine overall prediction. During real operation the temperature that will conduct the work exchange at the turbine will be lower than the measured at turbine inlet. That is due to the heat transferred from the exhaust gases to the turbine volute and later to the housing case. That heat flux will be partly recovered by the lubricating oil and the coolant liquid in case it exists. For low load points part of the heat from the turbine can achieve the compressor case worsening its efficiency. 

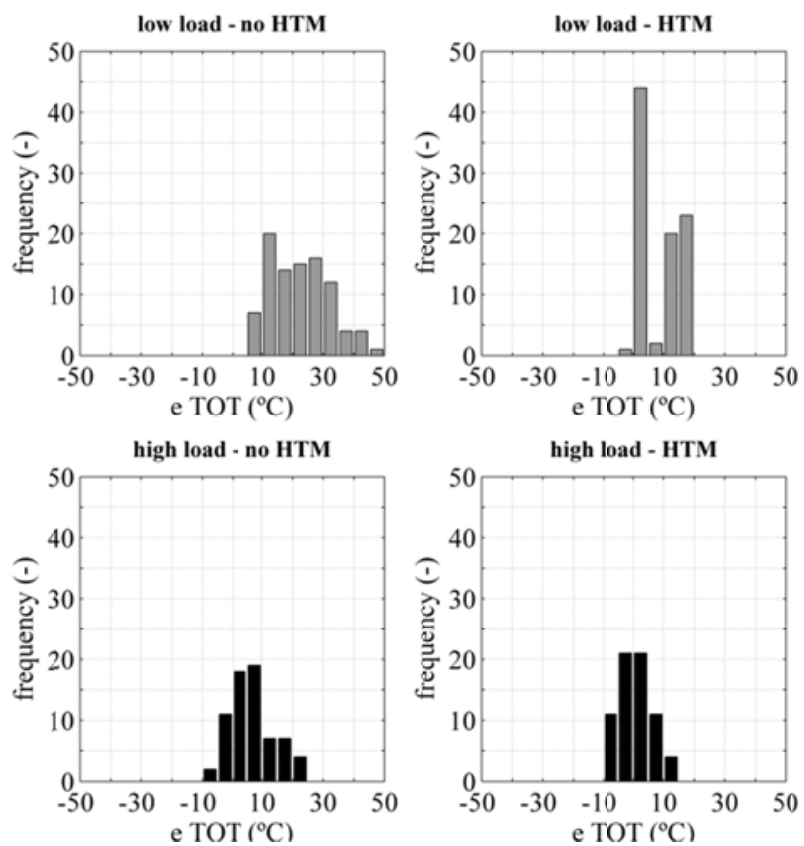

Figure 10. Turbine Error distribution of HTM turbocharger \#1 \& \#2.
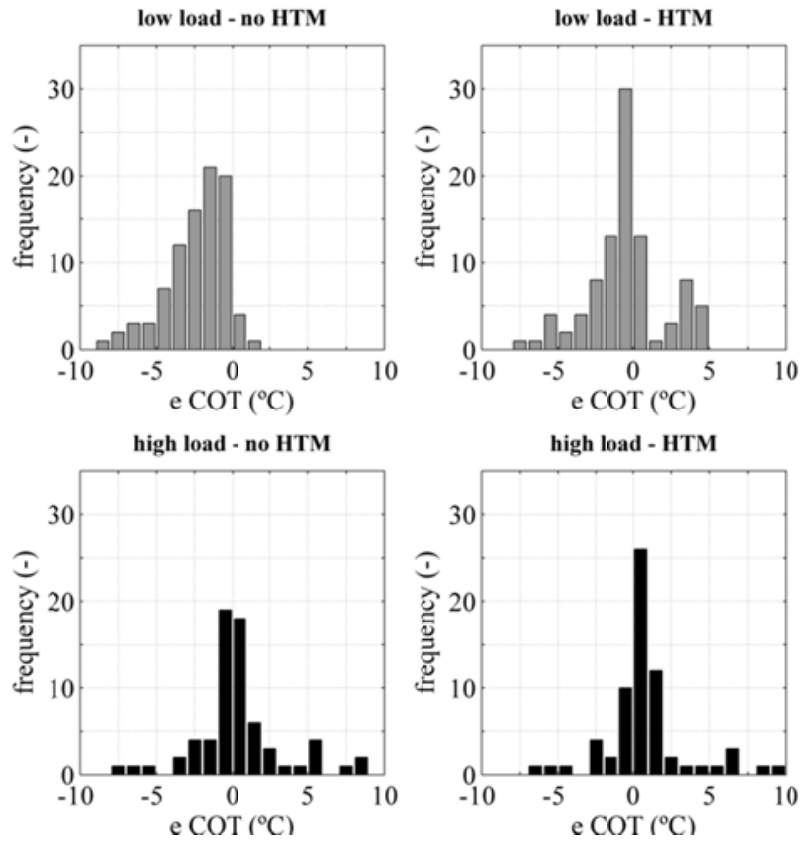

Figure 11. Compressor Error distribution of HTM turbocharger \#1 and \#2.

In case the HTM is not used in simulations, error predicting turbine outlet temperature will be higher and positive in a range between $15^{\circ} \mathrm{C}$ and $30^{\circ} \mathrm{C}$ higher than with HTM. That is due to the fact that no heat has been removed at the turbine volute and so modeled TOT will be bigger than the measured one. Figure 10 shows in a histogram fashion the error predicting turbine outlet temperature. The height of the bars represents the number of simulated operative points having an error in COT equal to the represented in abscissas axis. As shown in the histogram, when the HTM is used (column on the right) error drastically reduces since there are less simulated points in the limits and most concentrated around zero. It is also observed how when HTM is used results show a distribution centered in zero both for the higher powers and for the lowers. Figure 11 shows error distribution predicting compressor outlet temperature (COT). As it is observed for both the low load and high load regions error reduces when HTM is used and the height of the corresponding bar to zero error increases noticeably. Clearly, for the low load cases, results show a distribution centered in zero.
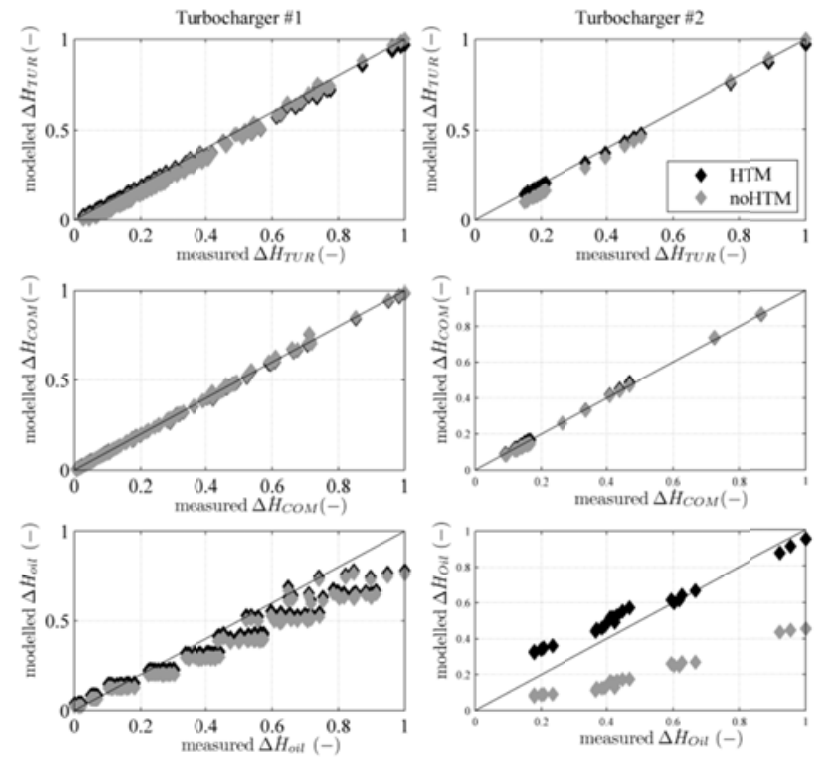

Figure 12. Power Balance in turbocharger simulations.

Figure 12 shows the agreement between simulated and measured turbocharger enthalpy drops considering or not heat transfer effects. Enthalpy drops have been put into dimensionless form. As Figure 12 shows, when heat transfer effects are not taken into account to perform 1D simulation, the modeled turbine enthalpy drop is lower than the measured one. That is due to modeled turbine outlet temperature is higher than in the case of including HTM. The reason is that no heat flux has been removed before the expansion process from the exhaust gases to the turbine case and later to housing case. With respect to the predicted compressor enthalpy gain, for both turbochargers the effect of taking into account the HTM is not noticeable for the used scale covering the whole operative range. Nevertheless, Figure 11 showed a better prediction in compressor outlet temperature and consequently better prediction in compressor enthalpy change. With respect to the power exchanged in the oil, it will include the increase in outlet oil temperature due to friction losses but also due to heat transfer from metal nodes to the oil according to the lumped model in Figure 3. 
The latter one will be only considered in case HTM is used in simulations. In case of turbocharger \#1 no big differences predicting oil power are observed when the HTM is used or not. That is due to that turbocharger is water cooled acting that circuit as a sink and so the heat transmitted to the oil is almost negligible. However in case of turbocharger \#2 that does not have a cooling port, the importance of the HTM is noticeable. In that way, when HTM is not used (grey points) the modeled power to the oil reduces drastically compared to the measured power as only the contribution of friction losses in oil heat up are considered but not the heat fluxes from the turbocharger. A consequence of the big differences predicting turbocharger enthalpy changes, when a HTM is not used, can be observed in terms of the error in turbocharger speed prediction as showed Figure 13. As it is observed, prediction in turbocharger speed improves when HTM is used and mainly at low turbine power areas.

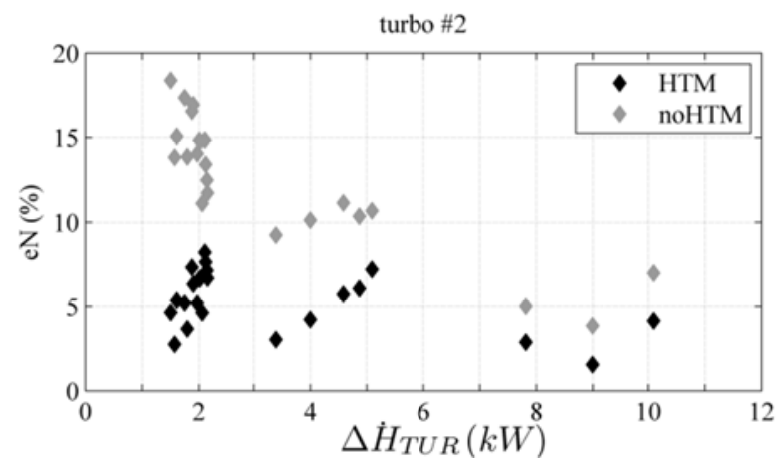

Figure 13. Error in turbocharger speed for hot steady simulations (Turbo \#2)
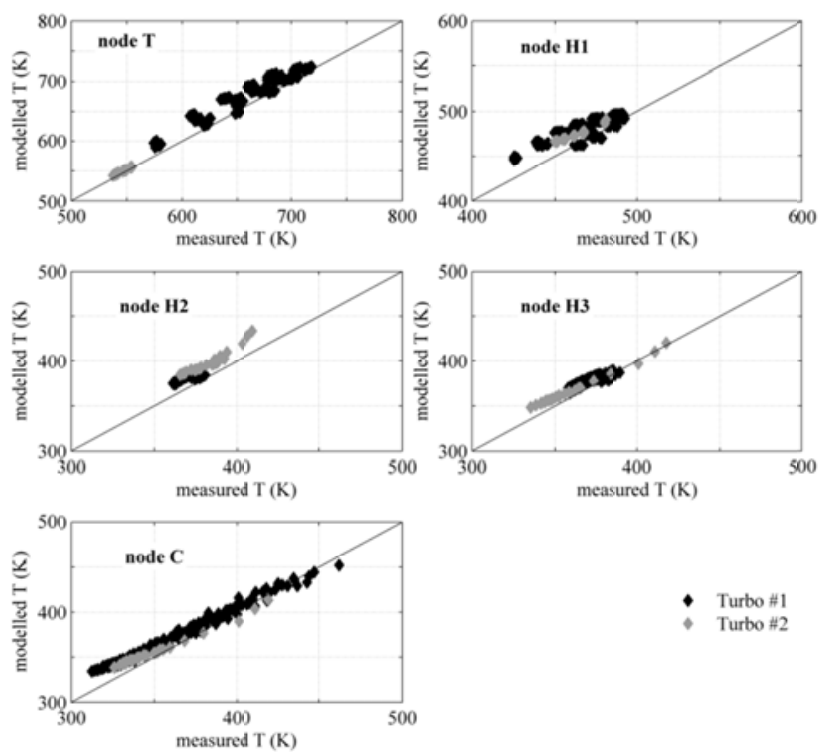

- Turbo \#1

- Turbo \#2

Figure 14. Temperature prediction at metal nodes

The proposed thermal model also calculates wall temperatures for the turbocharger metal nodes introduced in Figure $3(\mathrm{~T}$, Page 9 of 12
$\mathrm{H} 1, \mathrm{H} 2, \mathrm{H} 3, \mathrm{C})$. In Figure 14 wall temperature prediction at each of the metal nodes is compared with the measured ones. As it is observed the model provides a good prediction for both turbochargers for the different nodes.

\section{Discussion of pulsating flow results}

Apart from modeling steady flow tests, the turbocharger HTM model has been used to simulate points under pulsating hot operative conditions at the turbine as showed in Table 2 .

\begin{tabular}{|c|c|c|c|}
\hline \multicolumn{2}{|c|}{ Turbo \#1 } & \multicolumn{2}{c|}{ Turbo \#2 } \\
\hline $\mathbf{N}(\mathbf{r p m})$ & $\mathbf{T I T}\left(\mathbf{~}^{\mathbf{}} \mathbf{C}\right)$ & $\mathbf{N}(\mathbf{r p m})$ & TIT $\left({ }^{\mathbf{}} \mathbf{C}\right)$ \\
\hline 44502 & 299 & - & - \\
\hline 63538 & 381 & - & - \\
\hline 80332 & 387 & 77038 & 316 \\
\hline 84323 & 373 & 84206 & 329 \\
\hline 112055 & 427 & 96864 & 369 \\
\hline 122772 & 429 & 125744 & 392 \\
\hline 125330 & 401 & 126117 & 364 \\
\hline 138690 & 396 & - & - \\
\hline 152580 & 400 & - & - \\
\hline 152635 & 400 & - & - \\
\hline 152778 & 400 & - & - \\
\hline- & - & 171004 & 421 \\
\hline- & - & 189471 & 433 \\
\hline
\end{tabular}

Table 2- Turbochargers pulsating hot conditions

For that purpose the gas stand has been adapted with pulse generator consisting in a rotary valve placed at the turbine inlet simulating what would be the opening of exhaust valves. Pulses frequency and amplitude can be adjusted to generate the pulsating flow from a wide variety of operative conditions $[26,36]$. The lumped model is prepared to calculate all heat fluxes inside the turbocharger and also nodes temperature prediction at each time step when it is connected to the gasdynamic code OpenWAM [32]. Measurements and simulations for hot pulsating flow operative points have been performed. Figure 15 shows the average turbine temperature drop for the measured ( $\mathrm{x}$ axis) and the modeled (y axis) results by using the HTM (black points) or not using the HTM (grey points). Those temperature drops have been calculated from the averaged instantaneous inlet and outlet turbine temperatures. As it is observed when HTM is used a much better prediction in turbine temperature drop is obtained. That improvement is more evident for the low load points (small temperature drops) the same trend that it was observed for the steady flow points. The error predicting turbine enthalpy drop will be transferred to the prediction of turbocharger speed. As it was observed for the steady flow conditions, error predicting turbocharger speed increases as engine load reduces as showed in Figure 16. 

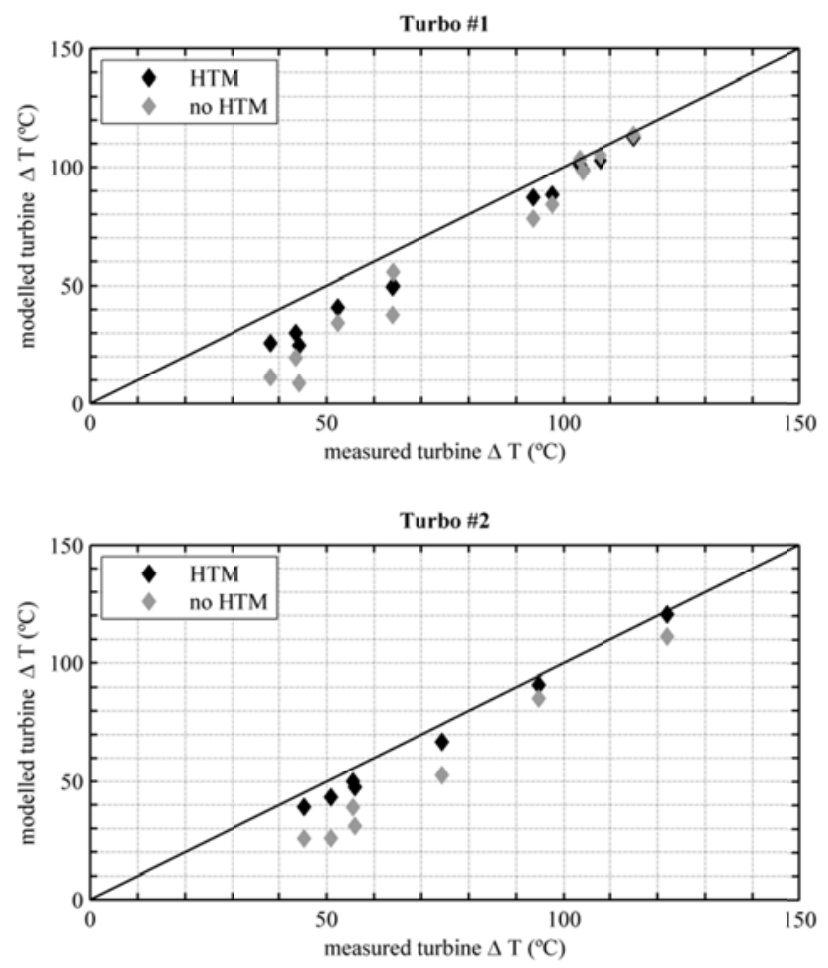

Figure 15. Error predicting average turbine temperature drop with pulsating flow conditions (turbo \#1 and turbo \#2).

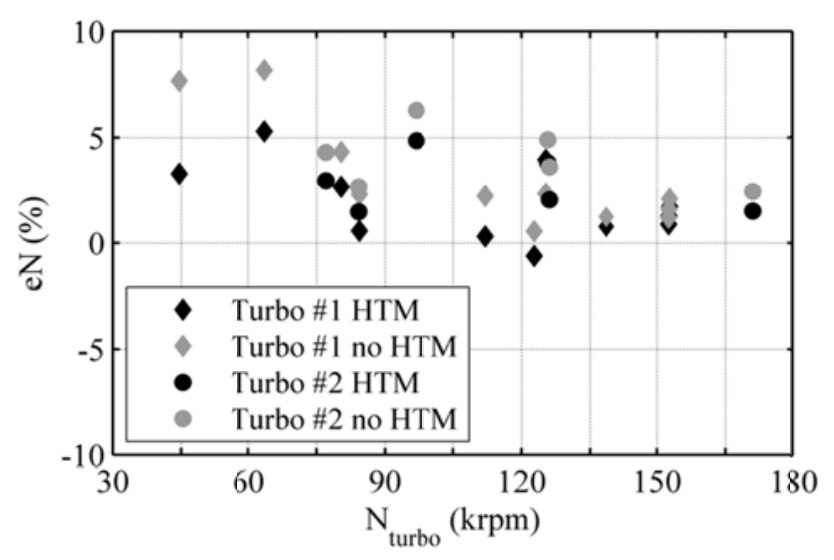

Figure 16. Error predicting turbocharger speed (hot
pulsating flow conditions)

\section{SUMMARY/CONCLUSIONS}

The results of a lumped model to calculate the heat fluxes inside automotive turbochargers have been presented. The model is adapted to be used in turbochargers with or without coolant circuit. The HTM takes into account metal conduction between turbocharger components but also convection between working fluids (exhaust gases, compressed air, lubricating oil, ambient air and coolant liquid) and metal nodes. The heat exchange process at the turbine is simplified Page 10 of 12 by considering that it takes place only before the expansion process.

At the compressor side the heat transfer is considered to take place in two stages, before and after the compression process. Two turbochargers have been tested under steady and pulsating hot flow conditions in order to analyze the importance of heat transfer fluxes.

It has been observed how heat fluxes become more important for the overall turbocharger prediction when the turbocharger load reduces. In some cases the heat transferred from the exhaust gases to the rest of the turbocharger via turbine case can achieve the $50 \%$ of the total turbine enthalpy drop. Similar tendency is observed for the compressor.

It has been observed that when the proposed HTM is used error predicting compressor and turbine outlet temperatures drastically reduces. This improvement is clearly observed for the low load points where differences modeling turbine outlet temperature are centered on cero and the dispersion is reduced. Same results are observed for turbine outlet temperature prediction under pulsating flow conditions.

\section{REFERENCES}

1. Shaaban, S., Seume, J., Berndt, R., Pucher, H., and Linnhoff, H., "Part-load Performance Prediction of Turbocharged Engines", Proceedings of 8th International Conference on Turbochargers and Turbocharging, C647/019, Woodhead Publishing and CRC Press LLC, London, 2006.

2. Galindo, J., Luján, J., Serrano, J.R, Dolz, V., and Guilain, S., "Description of a Heat Transfer Model Suitable to Calculate Transient Processes of Turbocharged Diesel Engines with One-Dimensional Gas-Dynamic Codes" Applied Thermal Engineering (26): 66-76, 2006.

3. Podevin, P.,Toussaint M., Richard G., and Farinole, G., "Performances of Turbocharger at Low Speed", Proceeding of the SYMKOM02 congress, Lodz, Pologne, 2002.

4. Guzzella, L., Wenger, U., and Martin, R., "IC-engine Downsizing and Pressure-Wave Supercharging for Fuel Economy", SAE Technical Paper, 2000-01-1019, 2000, doi: 10.4271/2000-01-1019.

5. Soltic, P., "Part-Load Optimized Si Engine Systems", Ph.D. thesis, Swiss Federal Institute of Technology, Zurich, 2000.

6. Guzzella, L., "Introduction to Modeling and Control of Internal Combustion Engine Systems", Springer, 2009.

7. Mrosek, M., and Isermann, R., "On the Parametrisation of the Turbocharger Power and Heat Transfer Models", IFAC AAC 2010, Munich, Germany, 2010.

8. Shaaban, S., "Experimental Investigation and Extended Simulation of Turbocharger Non-Adiabatic Performance", Ph.D. thesis, University of Hannover, Germany, 2004.

9. Olmeda, P., Arnau, F.J., Dolz, V., and Reyes-Belmonte, M.A., "Determination of heat flows inside turbochargers 
by means of a one dimensional lumped model", Mathematical and Computer Modeling, 2011. doi: 10.1016/j.mcm.2011.11.078

10. Verstraete, T., Alsalihi, Z., and Van den Braembussche, R., "Numerical study of the heat transfer in micro gas turbines", Journal of Turbomachinery (129): 835-841, 2007.

11. Shah, P., and Tan, C., "Effect of blade passage surface heat extraction on axial compressor performance", Journal of Turbomachinery, (129): 457-67, 2007.

12. Rautenberg, M., Mobarak, A., and Molababic, M., "Influence of heat transfer between turbine and compressor on the performance of small turbochargers", JSME Paper 83-Tokyo-IGTC-73. International Gas Turbine Congress, 1983.

13. Cormerais, M., Hetet, J., Chessé, P., and Maiboom, A., "Heat Transfer analysis in a turbocharger compressor: Modelling and Experiments", SAE Technical Paper 200601-0023, 2006.

14. Watson, N., and Janota, S., "Turbocharging the internal combustion engine", MacMillan Publisher Ltd, London,. ISBN 0333242904, 1982.

15. Shaaban, S., and Seume, J., "Impact of turbocharger nonadiabatic operation on engine volumetric efficiency and turbo lag", International Journal of Rotating Machinery, 2012.

16. Pucher, H., Berndt, R., and Grigoriadis, P., "Erweiterte darstellung und extrapolation von turbolader-Kennfeldern als randbedingung der motorprozesssimulation", $F V V$ Informationstagung Motoren Heft R513, Frankfurt, Germany, 2001.

17. Baines, N., Wygant, K., and Dris, A., "The analysis of Heat Transfer in Automotive Turbochargers", Proceedings of ASME Turbo Expo 2009, GT2009-59618, 2009

18. Chesse, P., Chalet, D., and Tauzia, X., "Impact of heat transfer on the performance calculations of automotive turbocharger compressor", Oil \& Gas Science and Technology, IFP Energies nouvelles, 2011.

19. Bohn, D., Heuer, T., and Kusterer, K., "Conjugate flow and heat transfer investigation of a turbocharger: Part I: Numerical results", ASME paper, GT2003-38445, 2003.

20. Shaaban, S. and Seume, J., "Analysis of turbocharger non-adiabatic performance",

Turbochargers and Turbocharging, Inst Mech Engineers, 2006, 119-130

21. Bohn, D., Moritz, N., and Wolff, M., "Conjugate flow and heat transfer investigation of a turbocharger: Part II: Experimental results", ASME paper, GT2003-38449, 2003.

22. Yamagata, A., Nagai, S., and Kawakubo, T., "Prediction and measurement of turbocharger compressor wheel temperature", Proceedings of 8th International Conference on Turbochargers and Turbocharging, Woodhead Publishing and CRC Press LLC, London, 2006.

23. Sidorow, A., Isermann, R., Cianflone, F., and Landsmann, G., "Comparison of a turbocharger model based on isentropic efficiency maps with a parametric approach based on Euler's turbo-machinery equation", 18th IFAC World Congress, Milano (Italy) August 28 - September 2, 2011.

24. Romagnoli, A., and Martinez-Botas, R., "Heat transfer analysis in a turbocharger turbine: An experimental and computational evaluation", Applied Thermal Engineering, 38, 58-77, 2012.

25. Torregrosa, A. J., Olmeda, P., Martín, J., and Romero, C., "A Tool for Predicting the Thermal Performance of a Diesel Engine", Heat Transfer Engineering, 32, 891-904, 2011.

26. Payri, F., Galindo, J., Serrano, J.R., and Reyes-Belmonte, M.A., "Experimental methodologies for a comprehensive characterization of automotive turbochargers", 13th EAEC European Congress, Valencia, Spain, 2011.

27. Serrano, J.R., Olmeda, P., Páez, A., and Vidal, F., “An Experimental Procedure to Determine Heat Transfer Properties of Turbochargers", Measurement Science and Technology, 21, 14pp, 2010.

28. Torregrosa, A.J., Broatch, A., Olmeda, P., and Martín, J., "A Contribution to Film Coefficient Estimation in Piston Cooling Galleries", Experimental Thermal and Fluid Science, 34, 142-151, 2010.

29. Incropera, F., and De Witt, D., "Fundamentals of Heat and Mass Transfer", John Wiley and Sons Inc.,New York, NY, 1985

30. Serrano, J.R., Olmeda, P., Tiseira, A., García-Cuevas, L.M., and Lefebvre, A., "Importance of mechanical losses modelling in the performance prediction of radial turbochargers under pulsating flow conditions" $S A E$ Technical Paper, 2013

31. Galindo, J., Serrano, J.R., Arnau, F.J., and Piqueras, P., "Description and analysis of a one-dimensional gasdynamic model with Independent Time Discretization", Proceedings of the Spring Technical Conference of the ASME Internal Combustion Engine Division, pp. 187197, Chicago, 2008.

32. OpenWAM web-site, CMT-Motores Térmicos, UPVUniversidat Politècnica de València. www.Openwam.org

33. Payri, F., Serrano, J.R., Fajardo, P., Reyes-Belmonte, M.A., and Gonzalo-Belles, R. "A physically based methodology to extrapolate performance maps of radial turbines" Energy Conversion and Management, 2012, 55, 149-163

34. Torregrosa, A.J., Galindo, J., Serrano, J.R., and Tiseira, A., "A procedure for the unsteady characterization of turbochargers in reciprocating internal combustion engines", The 4th International Symposium on Fluid Machinery and Fluid Engineering, November 24-27, 2008, Beijing, China, 2008

35. Torregrosa, A.J., Arnau, F.J., Piqueras, P., ReyesBelmonte, M.A., "Acoustic One-Dimensional Compressor Model for Integration in a Gas-Dynamic Code" - SAE Technical Paper 2012-01-0834, doi:10.4271/2012-01-0834.

36. Serrano, J.R, Arnau, F.J., Fajardo, P., Vidal, F., and Reyes-Belmonte, M.A., "Contribution to the modeling

Page 11 of 12 
and understanding of cold pulsating flow influence in the efficiency of small radial turbines for turbochargers"

Journal of Engineering for Gas Turbines and Power, Vol 134, Issue10, (10 p) 2012

\section{ACKNOWLEDGMENTS}

The authors of this paper wish to thank M.A. Ortiz and V.

T, Tur Turbine

W

Cooling liquid

$\dot{W}$

Power

Ucedo for their worthy assistance on the machining and

measurement processes, and also L.M. García-Cuevas for his invaluable assistance in computer programming.

\section{DEFINITIONS/ABBREVIATIONS}

$\Delta \dot{\mathrm{H}}$

$\Delta \mathrm{T}$

1D

bc

C, Com

CFD

e

FEM

HTM

$\mathrm{i}, \mathrm{j}$

IC

IT

K

$\mathrm{Nu}$

OC

OD

OT

$\operatorname{Pr}$

$\operatorname{Re}$

$Q, \dot{Q}$
Enthalpy power drop (W)

Temperature drop $\left({ }^{\circ} \mathrm{C}\right)$

One Dimensional

Boundary conditions

Compressor

Computational Fluid Dynamics

Error

Finite Elements Method

Heat Transfer Model

Consecutive nodes in the lumped model

Inlet Compressor

Inlet Turbine

Metal conductance

Nusselt number (-)

Outlet Compressor Case

Outlet Compressor Diffuser

Outlet Turbine

Prandtl number (-)

Reynolds number (-)

Heat Flux (W) 